\title{
A 425-year precipitation history from documentary weather anomalies and climate records at Palermo, Italy
}

Nazzareno Diodato

Monte Pino Research Observatory on Climate and Landscape, GTOS/TEMS, Benevento, Italy; nazdiod@tin.it

For southern Europe, especially mediterranean Italy, our knowledge of environmental and climatic variations has until now been discontinuous or founded on very few multisecular precipitation series (Cantù and Narducci, 1967; Brunetti et al., 2004). Fortunately, the Italian area offers a wide range of descriptive documentary data (i.e., reports from chronicles, daily weather reports, religious ceremonies, local books, etc.), that makes this area ideal for climate reconstructions on various time and spatial scales prior to the instrumental period (Enzi and Camuffo, 1996; Diodato, 1999; Luterbacher et al., 2005). The pre-instrumental epoch includes the so-called Little Ice Age (LIA), variously assessed as AD $1300-1900$, that is not expected to be homogeneous and sustained over large climatic regions (Bradley and Jones, 1993). So, climatic research at regional and sub-regional scales for the pre-instrumental epoch is useful for understanding the nature of climate variability on multi-decadal and longer timescales. In the last decades, several studies have reported climate reconstructions in some European localities based on documentary sources (for a synthesis see Brádzil et al., 2004). This research suggests that pre-instrumental documentary indices are promising tools for the reconstruction of rainfall and thermal regime fluctuation. In this way, precipitation history for southern Europe during the period 15802004 AD was analyzed at the Palermo Astronomical Observatory (Sicily, Italy; Fig. 1a).

\section{Data and methods}

The Sicily region is characterized by a typical Mediterranean regime, with very dry summers and moist cold seasons (Autumn-Winter) when most precipitation occurs. Climate in Palermo Province is represented by both steppe-lake and semi-arid zones (Fig. 1b). Historical written records of weather conditions that affect agricul-

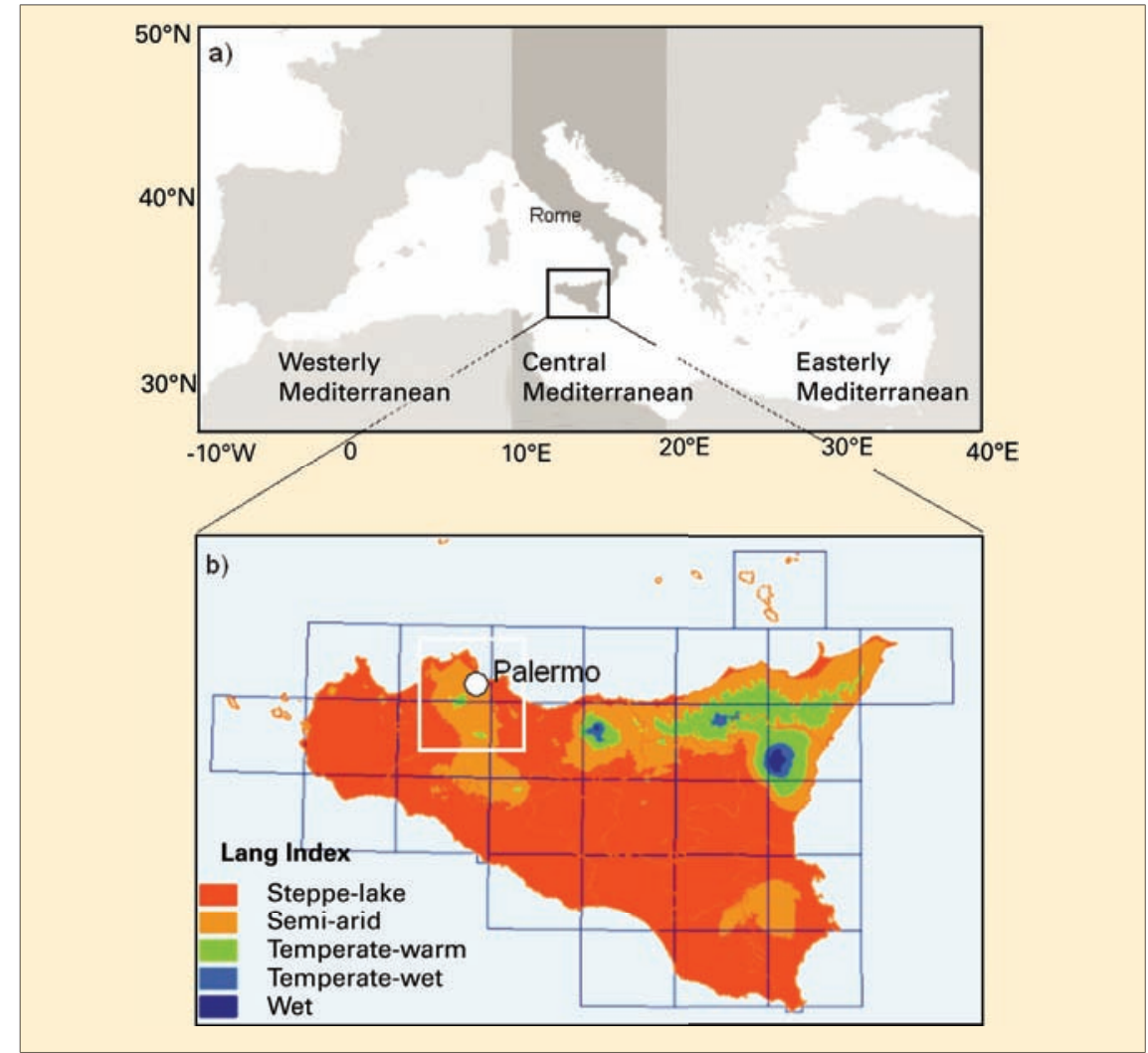

Fig. 1: Geographic location (a); map of the Lang Index (b) with Palermo Province (white square box) and Palermo Observatory (white circle).

ture and living conditions have been taken as a proxy for instrumental observations of the relative wetness and dryness. Data were compiled from various kinds of documents, including chronicles (Moio and Susanna, 1500-1769), annals (Corradi, 1865-94), archival records (Piervitali and Colacino, 2001) and two databanks of the SICI-CNR Project (available online at http://sici.irpi.cnr.it/giano.htm), referring mainly to Palermo Province (Fig. 1b). As a consequence, a numerical index was established to characterize the rainfall regime and its evolution. The compilation of the data is based on the method introduced by Pfister (1988). However, in this work, due to the regional climate peculiarities, the weather anomalies related to rainfall were coded following the modified classification of Rodrigo et al. (1998): meteorological drought from October to April (Precipitation Index, $\mathrm{PI}=$ $-1)$; meteorological droughts in May or September $(\mathrm{PI}=-0.5)$; since precipitation is almost zero during the summer, PI was halved for June, July and August $(P I=0)$; intensive and/or continuous rains $(\mathrm{PI}=+1)$; rains with floods $(P I=+2)$. When the authors did not comment on the meteorological conditions, the situation was considered as 'normal' and was assigned the index $\mathrm{PI}=0$. Rodrigo's indices were modified to weighted seasonal indices by minimizing the sum squared errors (SSE) between the Annual Rainfall Anomalies (ARA) and Precipitation Index Sum (PIS) in the calibration period - overlapping indexed and measured precipitation records (1839-1868) - as:

$$
\mathrm{SSE}=\sum_{\mathrm{j}=1}^{\mathrm{N}}\left(\mathrm{ARA}_{\mathrm{j}}-\mathrm{PIS}_{\mathrm{j}}\right)^{2}
$$

where PIS is the sum of the monthly index for each year, j. Using the PIS index as the independent variable and measured annual rainfall anomalies as the dependent variable, a determination coefficient value, $r^{2}$ $=0.64$ (statistically significant at the 


\section{Science Highlights}

$95 \%$ confidence level by a t-test), derived from the following linear equation: $\mathrm{EPA}=(19.41+50.76 \cdot \mathrm{PIS})$; where EPA is the Estimated Precipitation Anomalies ( $\mathrm{mm}$ ), corresponding to the estimated value of total annual rainfall anomalies. Finally, annual reconstructed precipitation (RP) were computed following Fritts et al. (1979) by multiplying each value by the empirical standard deviation of instrumental data (SDMPA), and dividing it by the empirical standard deviation of estimations (SDEPA), as: RP = (EPA - (SDMPA / SDEPA) + PM); where the standard deviation ratio is equal to 1.35 and $\mathrm{PM}$ is the precipitation mean $(\mathrm{mm})$ estimates over the calibration period. The non-parametricThom test (Thom, 1966) was also performed, resulting in a homogeneous series.

\section{Results}

The final result of the precipitation reconstruction is shown in Figure 2a, allowing a preliminary view of temporal evolution of annual RP from 1807 onwards, where instrumental data (Micela et al., 2001) began. That is, after several years of high climatic variability (from 1660 to 1930) during the first three centuries of the series, a period of lower climatic variability followed (from 1940 to 2000). In particular, the 18th century was punctuated with alternating extreme drought and wet periods (including frequent floods), which exceeded the 10th and 90th percentiles, respectively. In order to identify possible climatic change, Standardized $\mathrm{Cu}$ mulative Anomalies (SCA) was also computed after Mächel et al. (1998) and Jacobeit et al. (2001). Thus, sustainably declining/rising values in cumulative anomalies indicate the prevalence of negative/positive annual anomalies, and major turning points in cumulative anomalies indicate transitions between periods predominated by contrasting annual anomalies. However, this method does not identify the character of the change or the stability of the series before and after the change point, so the results should be considered cautiously. Figure 2b illustrates the SCA series. It reveals notable and marked differences between the periods before and after the 20th century, with

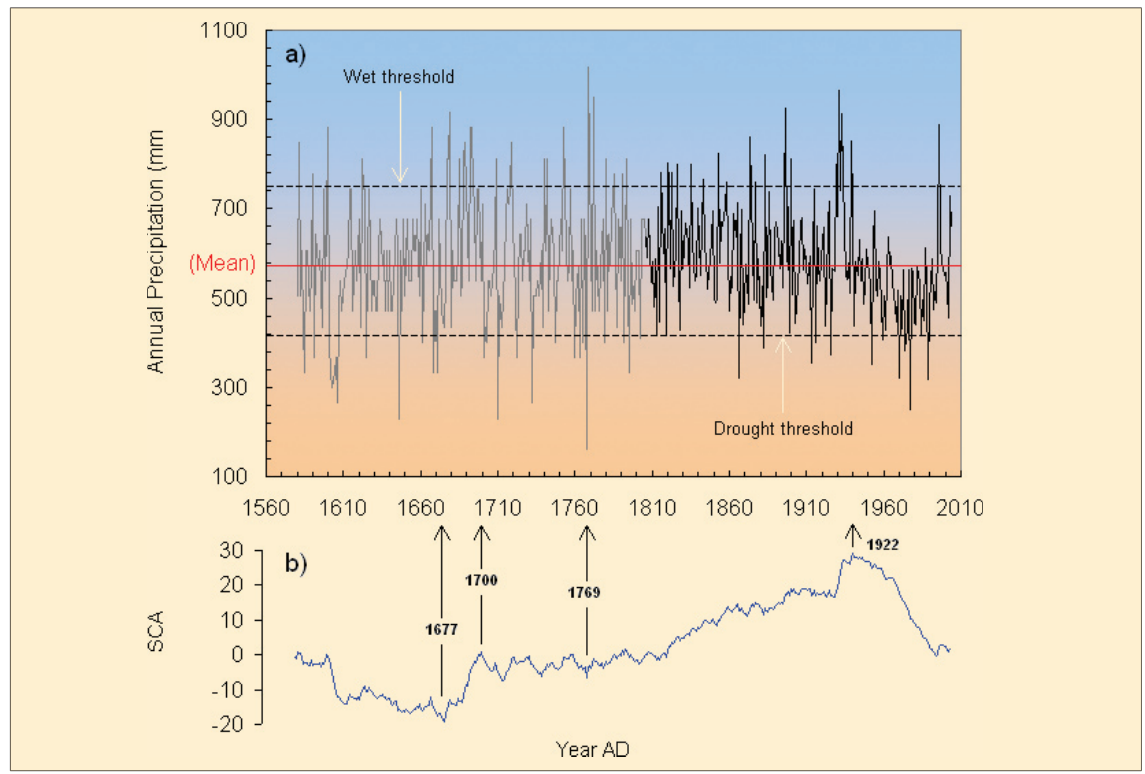

Fig. 2: Historical precipitation series (1580-2004) at Palermo Astronomical Observatory (a) grey line: precipitation reconstructed; black line: instrumental data from 1806 onwards; horizontal red line: mean value; dashed lines: threshold corresponding to 10th and 90th percentiles. Standardized Cumulative Anomalies (SCA) (b) with changes in 1677, 1700, 1769 and 1922 in the precipitation series.

some particular contrasts in each of sub-time series. Thus, SCA indicates a change in the slope of the curve in the years 1677, 1700, 1769 and 1922 AD. The length of these periods reveals no regular pattern. Notable was the wet period between 1677-1700 that appears to be within the Maunder Minimum (1675-1715 AD), indicating that solar activity is likely an important forcing of climatic change in the study region, in according with findings from Greece (Xoplaki et al., 2001) and Spain (Barriendos, 1997). The longer and last wet phase is recorded between 1769 and 1922 AD.

\section{Conclusions}

Longer timescale series are important to understanding climatic variations on multi-decadal and centennial timescales. In this paper, documentary sources were an important proxy in a first and preliminary investigation of precipitation fluctuation for an Italian island of the Central Mediterranean (Sicily). Over the last 5 centuries, different climatic epochs have alternated with the respective transitions periods: the Little Ice Age and the Present-Day Warming with transition sub-periods. The last period of the 20th century rainfall series shows a behavior dissimilar to those of other periods in the past, with a reduction of the climate variability and a strong decrease of precipitation amount. This is in contrast to very recent years that again show rainfall peaks that could increase the environmental risk connected with the sensitive landscape.

More information about Global Terrestrial Observing System/Terrestrial Ecosystem Monitoring Sites (GTOS/TEMS) can be found at: www. fao.org/gtos/tems/index.jsp

\section{ACKNOWLEDGEMENTS}

Thanks to Dr. Vincenzo luliano (Palermo - Astronomical Observatory, University of Study) who facilitated the data collection on the precipitation series.

\section{REFERENCES}

Bradley, R.S. and Jones, P.D., 1993: Little Ice Age summer temperature variations: their nature and relevance to recent global warming trend. The Holocene, 3: 367-376.

Brádzil, R., Pfister, C., Wanner, H., Von Storch, H. and Luterbacher, J., 2004: Historical climatology in Europe - the state of the art. Climatic Change, $\mathbf{7 0}$ : 363-430.

Brunetti, M., Maugeri, M., Monti, F. and Teresa, N., 2004: Changes in daily precipitation frequency and distribution in Italy over the last 120 years. Journal of Geophysical Research, 109: D05102, doi:10.1029/ 2003JD004296.

Jacobeit, J., Jönsson, P., Bärring, L., Beck, C. and Ekström, M., 2001: Zonal indices for Europe 17801995 and running correlations with temperature. Climatic Change, 48: 219-241.

Rodrigo, F.S., Esteban-Parra, M.J. and Castro-Diez, Y., 1998: On the use of the Jesuit private correspondence records in climate reconstructions: a case study from Castille (Spain) for 1634-1648 A.D. Climatic Change, 40: 625-645.

For full references please consult:

www.pages-igbp.org/products/newsletters/ref2006_1.html 